\title{
Tecnologia na educação: A sala de aula invertida no processo de ensino- aprendizagem em bioquímica
}

\author{
Maria Gabriela Silva Carneiro Monteiro*, Rosangela Vidal de Souza Araújo \\ ${ }^{1}$ Mestranda em Educação, Programa de Pós- Graduação em Educação, Universidade Federal de Pernambuco. \\ ${ }^{2}$ Departamento de Morfologia e Fisiologia Animal, Universidade Federal Rural de Pernambuco. \\ e-mail:gabrielamonteiroobio@gmail.com
}

\begin{abstract}
The use of the flipped classroom (FC) methodology in biochemistry learning was investigated in the Biological Sciences degree course of a Federal Public Institution. The subjects were 20 students in the discipline of Systems Biochemistry with a workload of 60 hours. FC characterized as an approach by which the student must study the content and a face-to-face class as an extension and practical application of the studied concepts. To investigate, we conducted a descriptive, observational and field research with a qualitative approach. To collect the data, three activities related to the content of cellular respiration were applied, such as productions of the activities submitted to the content analysis. It was possible to observe strong evidence using the potential for using SAI in the formation of complex concepts in biochemistry, favoring the different learning styles of students. The data shown, despite the barriers to overcoming the progress of the experience, the implementation of learning models and innovative attitudes contributed a lot, especially for the student who gauges the penalty or learned in the discipline, showing what he learned during the class, solving problems, work collaboratively and make a difference in your future profession.
\end{abstract}

Keywords: Biochemistry teaching; blended learning; Flipped Classroom.

\section{Resumo}

O uso da metodologia da Sala de Aula Invertida (SAI) no aprendizado de bioquímica foi investigado no curso de Licenciatura em Ciências Biológicas de uma Instituição Pública Federal. Os sujeitos foram 20 estudantes da disciplina de Bioquímica dos Sistemas com uma carga horária de 60h. A SAl é caracterizada como uma abordagem pela qual o discente deve estudar previamente o conteúdo, servindo a aula presencial como ampliação e aplicação prática dos conceitos estudados. Para a investigação, foi realizada uma pesquisa descritiva, observacional e de campo com abordagem qualitativa. Para levantamento dos dados foram aplicadas três atividades ligadas ao conteúdo de respiração celular, cujas produções foram submetidas à análise de conteúdo. Foi possível constatar fortes evidências da potencialidade para o uso da SAI na formação de conceitos complexos em bioquímica, favorecendo os diferentes estilos de aprendizagem dos estudantes. Os dados obtidos mostram que, apesar das barreiras a superar no decorrer da experiência, a implementação de modelos de aprendizagem e atitudes inovadoras contribui muito, sobretudo para que o aluno faça valer a pena o que aprendeu na disciplina, mostrando que sabe tomar decisões adequadas, resolver problemas, trabalhar colaborativamente e fazer a diferença na sua futura profissão.

Palavras-chave: Ensino de Bioquímica; Ensino Hibrido; Sala de Aula Invertida. 
Pesquisa em Ensino: Tecnologia na educação: sala de aula invertida como potencializadora do ensinoaprendizagem de bioquímica

\section{Introdução}

A sociedade, de maneira geral, vem passando por transformações nos mais diversos setores, entre os quais está a educação. As escolas passaram por alterações, nas últimas décadas, e vêm buscando mudanças no ensino tradicional, que já não atende às demandas da contemporaneidade. Outro aspecto que passa por mudanças nas escolas e vem sendo bastante discutido é a introdução das tecnologias digitais de informação e comunicação (TDICs) nas aulas, que vêm provocando mudanças como a configuração de novos espaços de interação e de aprendizagem. Com isso, nesses espaços virtuais, o relacionamento professor-aluno-informação sofre uma mudança, na qual o papel do docente permite maior interação e participação do estudante, tanto lhe respondendo diretamente, como também apresentando novas informações a ele e à turma, visto que as tecnologias permitem o rápido e maior acesso ao conhecimento que está em constante mudança [1].

As metodologias ativas de aprendizagem destacam-se nesse contexto como alternativa inovadora necessária a essa finalidade, visto que conseguem unir as demandas inicialmente explicitadas: romper com a metodologia tradicional e introduzir as TDICs na sala de aula [2]. Elas têm sido amplamente divulgadas em universidades estrangeiras e vêm construindo diferenciais em instituições brasileiras que inseriram este referencial em sua organização metodológica, sobretudo em cursos de ensino superior da área da saúde [3]. Essas inovações baseiam-se em processos de aprendizagem que utilizam experiências reais ou simuladas, visando às condições de solução com sucesso de desafios presentes nas atividades essenciais da prática social em diferentes contextos. Entre as ações características desta metodologia está a escuta aos estudantes, valorização de suas opiniões, exercício da empatia, atenção aos questionamentos, encorajamento e respeito aos diferentes estilos de aprendizagem presentes em sala de aula [4]. Além disso, têm embasamento em teóricos que já vêm sendo estudados, como Paulo Freire, que se refere à educação como resultado da interação entre sujeitos por intermédio de suas palavras, ações e reflexões [5].

Quando há o vínculo das metodologias ativas às TDICs na prática pedagógica, passamos a dizer que está acontecendo o blended learning ou ensino híbrido. Este pode ser definido como um modelo de ensino-aprendizagem que ocorre em dois momentos (o presencial, em sala de aula, e o online, virtualmente) que se complementam e se misturam com objetivo de valorizar as interações e potencializar os vínculos, visto que a sala de aula passa a ser ampliada; além de tornar o aprendizado interessante e personalizado [6]. 
Pesquisa em Ensino: Tecnologia na educação: sala de aula invertida como potencializadora do ensinoaprendizagem de bioquímica

Há várias maneiras de aplicar o ensino híbrido nas instituições de ensino, como por exemplo, por meio das estratégias de rotação por estações, laboratório estacional e Sala de Aula Invertida [7]. Na modalidade de ensino híbrido, encontramos, conforme dito acima, um subgrupo denominado Sala de Aula Invertida ou flipped classroom. Nesse caso, diferente do que acontece na sala de aula tradicional, os discentes estudam as instruções e conteúdos virtualmente, antes da aula presencial, enquanto que o tempo em sala de aula física torna-se o momento de esclarecer dúvidas, bem como de realizar outras atividades, como aulas práticas, atividades em grupo, resolução de problemas, estudo de casos e discussões em grupo. Em outras palavras, tanto no momento anterior à aula presencial, como na sala de aula física, irá ocorrer uma aprendizagem ativa, na qual o aluno pode ir além do material que o professor disponibiliza virtualmente, buscando o que vai estudar e percorrendo sua trajetória de aprendizagem. Por esse motivo, o encontro presencial tornar-se um momento de debates riquíssimos. Já o professor, por sua vez, deixa de transmitir informações e passa a trabalhar as dificuldades e curiosidades dos alunos e a aprofundar o conhecimento com auxílio de dinâmicas diversas [8].

Essa metodologia de ensino, dentro do nível superior, pode ser uma alternativa na disciplina de bioquímica, carente de novas práticas que superem o aprendizado apenas por memorização. Alguns autores sustentam que, no ensino superior, essa mudança na metodologia do ensino tradicional encontra maior resistência para acontecer. Entre os fatores que justificam essa resistência estão as limitações na formação didática dos professores, a rigidez na estrutura curricular, a sobrecarga de funções, e, consequentemente, a falta de motivação dos docentes em debater novas metodologias de ensino-aprendizagem [9]. Para superar o modelo tradicional de ensino, é importante considerar todos os fatores que envolvem e influenciam o processo de ensinoaprendizagem, visto que esse processo é extremamente complexo e não se restringe apenas à aquisição de respostas ou mesmo de conhecimentos. Como está destacado abaixo:

(...) envolve inúmeras variáveis que se combinam de diferentes formas que estão sujeitas à influência de fatores externos, internos, individuais e sociais. A partir do reconhecimento dessas diferenças cognitivas e as adquiridas pelo meio em que vivem é possível programar estratégias de ensino para aperfeiçoamento do relacionamento entre os docentes e discentes, proporcionando, assim, maior efetividade e qualidade no processo ensino-aprendizagem [10]. ${ }^{\text {p. }} 2$

Diante disso, o artigo carregou como objetivo analisar a construção de uma 
Pesquisa em Ensino: Tecnologia na educação: sala de aula invertida como potencializadora do ensinoaprendizagem de bioquímica

aprendizagem sobre o metabolismo energético a partir da metodologia da Sala de Aula Invertida (SAI) no curso de Licenciatura em Ciências Biológicas de uma Universidade Pública do Nordeste.

\section{Metodologia}

\subsection{Natureza da pesquisa}

Originada de um projeto de iniciação científica, a pesquisa foi desenvolvida, inicialmente, com 23 alunos e terminou com 20. Estes pertenciam ao segundo período do curso de Licenciatura Plena em Ciências Biológicas, na disciplina Bioquímica dos Sistemas de uma Universidade Federal do Nordeste. Trata-se de uma disciplina formalmente lecionada no modelo presencial. Portanto, os momentos virtuais relatados nesta pesquisa ocorreram fora da carga horária oficial, basicamente em momentos extraclasse (em casa, ou qualquer outro local de escolha do discente), o que não acarretou a diminuição da carga horária presencial.

Foi realizada uma abordagem qualitativa, que permite uma compreensão pautada no contexto dos sujeitos, em um campo detalhado e dotado de significado dos dados obtidos. Nesse sentido, o papel do pesquisador é mais do que o de mero observador dos fenômenos, ele é um instrumento de pesquisa [11]. No caso das abordagens nesse método, pode ser feita uma análise de conteúdo que vai servir de base para uma análise qualitativa das entrevistas, das observações e de questões abertas em questionários. Esta análise permite compreender o significado dos dados coletados e também facilita o entendimento dos conteúdos mediante alguma classificação apresentada de forma sistematizada, que pode ser a divisão em categorias ou pela contagem de palavras e termos contidos nas respostas. Tal investigação está baseada na análise de conteúdo de Bardin [12].

Do ponto de vista procedimental, esta é uma pesquisa documental e observacional, visto que foram utilizadas fontes diversificadas e dispersas, como gravações de voz, vídeos, atividades que representaram documentos institucionais, questionários e diário do pesquisador [13]. Esse tipo de pesquisa é importante não porque responde definitivamente a um problema, mas porque proporciona melhor visão desse problema ou, então, hipóteses que contribuem para reflexão do tema e conduzem a sua verificação por outros meios. A presente pesquisa também é caracterizada como um estudo de campo por ter a fonte de dados no próprio campo em que ocorrem os fenômenos e tem foco em um único grupo ou comunidade (estudantes de Licenciatura em Ciências Biológicas) em termos de sua estrutura social, ou seja, ressaltando a interação entre seus componentes [13]. 
Pesquisa em Ensino: Tecnologia na educação: sala de aula invertida como potencializadora do ensinoaprendizagem de bioquímica

\subsection{Organização dos momentos presenciais e virtuais}

Inicialmente, os estudantes foram apresentados à metodologia do ensino híbrido com foco no modelo da Sala de Aula Invertida (SAI) para que soubessem os seus novos papéis. Com isso, o Termo de Consentimento Livre e Esclarecido (TCLE) foi assinado pelos discentes que concordaram em participar da pesquisa.

Para adequar a turma à metodologia da Sala de Aula Invertida, foi necessária a criação de um ambiente virtual no qual ocorrem discussões de temáticas, e há disponibilidade de fontes de estudo com o conteúdo específico para ser trabalhado ativamente em sala de aula. Os ambientes virtuais de aprendizagem, de um modo geral, assumem como principal característica a disponibilização de um conjunto de ferramentas com o objetivo de suportar a produção e a distribuição de conteúdos, a comunicação e a colaboração, e a avaliação do processo de ensino e aprendizagem [1]. Pensando nisso, as redes sociais, se utilizadas para fins pedagógicos, podem ser consideradas um ambiente virtual de aprendizagem (AVA). Assim, a turma decidiu, em acordo com a professora da disciplina, utilizar um grupo fechado na rede social Facebook.

Foi planejada a sequência didática virtual dentro do grupo fechado do Facebook (denominado Bioquímica dos Sistemas); também foram criados eventos que receberam o nome do conteúdo específico de cada bloco de assuntos referentes ao tema Respiração Celular. Nesses eventos, foram postados os materiais para o estudo prévio (atividades extraclasse), como mostrado na tabela 1, em que o tempo dedicado ao aprendizado desse material variou de acordo com o envolvimento do estudante na metodologia. Vale ressaltar que, na SAI, um dos principais objetivos é que o tema seja absorvido pelo aluno antes do momento presencial, e que este, tradicionalmente utilizado para apresentar o conteúdo, torne-se, agora, um momento de debate, de realização de atividades individuais e em grupo, bem como momento de elucidar possíveis dúvidas procedentes do estudo no ambiente virtual (momento extraclasse).

Tabela 1: Organização dos momentos virtuais (atividades extraclasse) da metodologia da SAI.

\begin{tabular}{|c|c|c|}
\hline EVENTOS & MATERIAL DISPONIBILIZADO & OBJETIVO PEDAGÓGICO \\
\hline Lipólise & 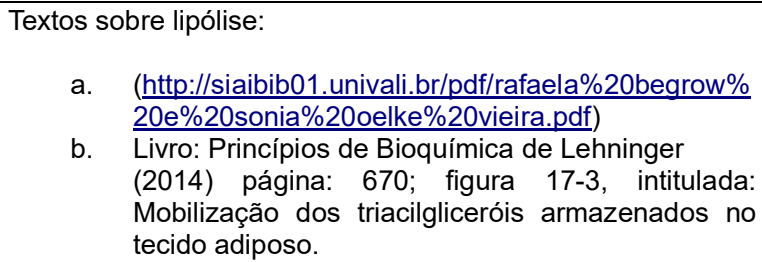 & $\begin{array}{l}\text { Proporcionar o entendimento conceitual } \\
\text { das condições para que ocorra a lipólise, } \\
\text { por meio da leitura. }\end{array}$ \\
\hline Betaoxidação & Postagem de vídeo e imagens: & $\begin{array}{l}\text { Proporcionar a visualização das reações } \\
\text { químicas que acontecem em cada etapa } \\
\text { da betaoxidação e estimular a reflexão } \\
\text { para ser trabalhada em sala sobre: a que }\end{array}$ \\
\hline
\end{tabular}


Pesquisa em Ensino: Tecnologia na educação: sala de aula invertida como potencializadora do ensinoaprendizagem de bioquímica

\begin{tabular}{|c|c|c|}
\hline & $\begin{array}{l}\text { a. Vídeo (https://youtu.be/v29W6CIYSpk) } \\
\text { b. Livro: Princípios de Bioquímica de Lehninger } \\
\text { (2014) página: } 672 ; \text { figura 17-6, intitulada: Entrada } \\
\text { de ácido graxo na mitocôndria pelo transportador } \\
\text { acil-carnitina/carnitina. } \\
\text { c. Link:http://unifenasresumida.blogspot.com/2012/0 } \\
\frac{3 / \text { seminario-4-metabolismodos-lipideos-1.html }}{\text { (figura da conversão do citrato em palmitoil-CoA). }}\end{array}$ & $\begin{array}{l}\text { se destina; como se articula com a } \\
\text { lipólise e o ciclo de Krebs. }\end{array}$ \\
\hline Ciclo de Krebs & $\begin{array}{l}\text { Gráficos: } \\
\text { a. Transcritos da dissertação intitulada: } \\
\text { Caracterização do treinamento físico experimental de } \\
\text { endurance em esteira adaptada através de } \\
\text { marcadores metabólicos energéticos, } 2010 \text {. }\end{array}$ & $\begin{array}{l}\text { Fomentar a análise de dados científicos } \\
\text { que tenham relação com o tema } \\
\text { abordado em sala de aula, e neste caso } \\
\text { contextualizado com o exemplo } \\
\text { trabalhado, a atividade física. }\end{array}$ \\
\hline $\begin{array}{c}\text { Cadeia } \\
\text { Transportadora de } \\
\text { Elétrons }\end{array}$ & $\begin{array}{l}\text { Postagem de vídeo e texto: } \\
\begin{array}{l}\text { a. https://youtu.be/iwYUmGO3gf8 } \\
\text { b. https://www.infoescola.com/bioquimica/cadeia- } \\
\frac{\text { respiratoria/\#: :text=A\%20cadeia\%20respirat\%C3 }}{\text { \%B3ria\%20ou\%20cadeia,pelo\%20processo\%20d }} \\
\text { e\%20respira\%C3\%A7\%C3\%A30\%20celular. }\end{array}\end{array}$ & $\begin{array}{l}\text { Ler e visualizar o caminho metabólico do } \\
\text { acetil-coA até a CTE. }\end{array}$ \\
\hline
\end{tabular}

Com relação aos momentos presenciais, estes somaram oito aulas com duração de 1hora e 40 minutos cada, sendo duas dedicadas ao tema lipólise; duas para betaoxidação, duas para ciclo de Krebs e duas para cadeia transportadora de elétrons. Nessas aulas, foram aplicadas diferentes estratégias de ensino divididas em: (1) Momento de esclarecimento de dúvidas/feedback da participação e ações no ambiente virtual de aprendizagem; (2) Atividades em grupo/individuais (envolvendo várias abordagens de ensino, como resolução de problemas, análise de dados, estudo de casos e produção de vídeos e áudios) e, por fim, (3) Socialização em grupo (discussão das dúvidas e dos resultados das atividades com o grande grupo).

Nas atividades coletivas, os estudantes escolheram um nome de identificação para seus respectivos grupos e criaram um evento no AVA com este nome. Esse microambiente serviu para organização dos trabalhos do grupo, bem como para facilitar as orientações da professora. Foram atividades que forneceram base para os alunos responderem às atividades utilizadas na análise. Desse modo, a pesquisa consistiu, primeiramente, na vivência da turma com a sala de aula invertida, sendo, no decorrer da metodologia, aplicadas três atividades: 2 com respostas escritas e 1 por gravação em formato de vídeo ou áudio, que foram examinadas segundo a análise de conteúdo de Bardin [12]. Esta análise será apresentada nos resultados.

\subsection{Atividades}

Para cada conteúdo específico foi feita uma atividade para análise da metodologia da SAI no aprendizado. Sabendo que aulas que utilizam metodologias ativas têm como 
Pesquisa em Ensino: Tecnologia na educação: sala de aula invertida como potencializadora do ensinoaprendizagem de bioquímica

princípio o respeito aos estilos de aprendizagem (EA) dos estudantes, para identificar esses estilos foi enviado para os discentes o link $^{1}$ do questionário VARK (Visual, AuralRead, Write and Kinesthetic).

As atividades planejadas e descritas na tabela 2 foram baseadas nos estilos de aprendizagem (EA) observados na turma, tanto para contemplar os pontos fortes de cada aluno, como também para fortalecer aquelas habilidades que não apareceram em destaque no resultado da aplicação do questionário. O modelo VARK utilizado é fundamentado na Neurolinguística, e seus tipos de EA indicam características e preferências individuais no processo de aprendizagem [15]. Dessa forma, o modelo apresenta 4 possibilidades para o estudante processar a informação que equivale a cada letra do VARK, sendo elas: V- visual; A- auditivo; R- Read/Write; K- Kinesthetic. Além dessas, dependendo das respostas, o VARK apresenta também a possibilidade de o aluno ter um resultado alto para características de dois ou mais estilos de aprendizagem, é o chamado aluno multimodal. Os resultados do questionário VARK, neste trabalho, mostraram que a maioria dos estudantes, equivalente a $16(68 \%)$, possui, como potencial mais forte de aprendizagem, o estilo multimodal. Em seguida, 3 (14\%) alunos da turma foram caracterizados com potencial no estilo cinestésico, ou seja, a preferência de estudo está relacionada ao uso da experiência e da prática simulada ou real [16]; e 2 (9\%) correspondem àqueles alunos que, para aprender, preferem informações que são ouvidas ou faladas, classificados no estilo auditivo.

Tabela 2: Atividades utilizadas para verificar o aprendizado a partir da metodologia da SAI

\begin{tabular}{|c|c|}
\hline ATIVIDADE & OBJETIVOS/INTENCIONALIDADE \\
\hline $\begin{array}{l}\text { ATIVIDADE 1: Atividade dos ursos hibernantes - foi fornecido } \\
\text { um texto, que tem como título: "Ursos gordos realizam } \\
\text { betaoxidação durante o sono" transcrito do livro Princípios de } \\
\text { Bioquímica de Lehninger (quadro 17-1) [17]. Nesta atividade, os } \\
\text { estudantes tiveram que identificar a influência dos aspectos } \\
\text { metabólicos para que seja possível a hibernação. }\end{array}$ & $\begin{array}{l}\text { Relacionar o conteúdo lipólise e betaoxidação com a respiração } \\
\text { celular. Esta atividade teve a intencionalidade de relacionar uma } \\
\text { situação prática (numa temática de Biologia) aos aspectos } \\
\text { teóricos e conceitos de bioquímica da respiração celular. }\end{array}$ \\
\hline ESTILO DE APRENDIZAGEM TRABALHADA: leitor/escritor. & \\
\hline $\begin{array}{l}\text { ATIVIDADE 2: Interpretação de dados - interpretar as diferentes } \\
\text { concentrações de variáveis metabólicas encontradas nos } \\
\text { diferentes tipos de fibras musculares, apresentados em uma } \\
\text { tabela que comparava essas diferentes características } \\
\text { metabólicas entre as fibras musculares tipo I, Ila e Ilb, } \\
\text { estimulando o olhar interdisciplinar, sobretudo com as } \\
\text { disciplinas de Histologia e Fisiologia. } \\
\text { ESTILO DE APRENDIZAGEM TRABALHADA: leitor, escritor e } \\
\text { visual. }\end{array}$ & $\begin{array}{l}\text { Trabalhar na produção coletiva de uma atividade com alto nível } \\
\text { de complexidade de análise de dados, numa tabela sobre a } \\
\text { temática: caraterísticas bioquímicas nos diferentes tipos de } \\
\text { fibras musculares e suas preferências por diferentes sistemas } \\
\text { energéticos. Esta atividade teve a intenção de treinar os } \\
\text { estudantes para analisar dados coletados de experimentos } \\
\text { científicos, nos quais eles puderam reconhecer conceitos gerais } \\
\text { do metabolismo dentro de situações reais; além de identificar a } \\
\text { importância de conhecer vias metabólicas e outras } \\
\text { características bioquímicas da célula, bem como praticar }\end{array}$ \\
\hline
\end{tabular}

1 https://vark-learn.com/questionario/ 
Pesquisa em Ensino: Tecnologia na educação: sala de aula invertida como potencializadora do ensinoaprendizagem de bioquímica

\begin{tabular}{|l|l|}
\hline & $\begin{array}{l}\text { atividades que fomentem a visão interdisciplinar implícita na } \\
\text { natureza da disciplina de Bioquímica. }\end{array}$ \\
\hline $\begin{array}{l}\text { ATIVIDADE 3: Simulação de uma entrevista sobre o caso na } \\
\text { Boate Kiss - foi disponibilizada a matéria publicada no Portal } \\
\text { G12. Com isso, os estudantes tiveram que simular uma } \\
\text { entrevista gravada em formato de vídeo ou áudio, na qual, } \\
\text { como biólogos, explicaram, do ponto de vista metabólico, os } \\
\text { motivos das mortes por intoxicação nesse incêndio. }\end{array}$ & $\begin{array}{l}\text { Explicar as causas metabólicas que ocasionaram as mortes no } \\
\text { referido caso, relacionando-as com a temática estudada: } \\
\text { intencionalidade de levar o estudante a aprender/treinar a } \\
\text { comunicação com a sociedade por meio de uma linguagem de } \\
\text { fácil compreensão, porém com bases científicas, bem como } \\
\text { fazer o estudante perceber a relação bioquímica x cotidiano. }\end{array}$ \\
\hline ESTILO DE APRENDIZAGEM TRABALHADO: leitor, auditivo. & \\
\hline
\end{tabular}

\section{Resultados e discussão}

\subsection{Análise de conteúdo}

A realização da análise de conteúdo de Bardin ocorreu em três etapas: pré-análise; exploração do material; tratamento dos resultados com inferências e interpretações [12]. Na primeira etapa, que corresponde à organização dos materiais, foi realizada a leitura flutuante das respostas das atividades para conhecer e estabelecer as primeiras impressões. Posteriormente, outras leituras foram realizadas, nas quais foi possível constatar os conceitos em bioquímica pelas frases e palavras específicas do conteúdo. Isto feito, as respostas semelhantes foram destacadas com a mesma cor e, em cada uma delas, foram geradas unidades de registro com seus respectivos núcleos de sentido, bem como códigos para os conceitos e para os alunos. Com o objetivo de preservar suas identidades, os estudantes foram identificados como E1, E2 e assim sucessivamente.

\subsection{Análise dos resultados da atividade 1:}

Esta atividade foi realizada individualmente, após um debate presencial e estudo no ambiente virtual. Com isso, os estudantes tiveram que responder, baseados em um texto transcrito do livro de bioquímica de Lehninger, a seguinte pergunta: "Em anexo, temos um texto com um comentário sobre a betaoxidação de animais hibernantes. Se você, futuro professor de Biologia, fosse trabalhar com esse texto sobre a temática de armazenamento e utilização de energia proveniente das gorduras para garantir ATP, calor e água suficientes para o período de hibernação, que conteúdos extras você traria para aula e que zooms você daria no texto para a completa compreensão do processo?"

Nesse sentido, na análise das respostas, foram destacadas, inicialmente, palavras como lipólise, lipogênese, glicólise e betaoxidação como unidades de registros. Até esta

2 http://g1.globo.com/rs/rio-grande-do-sul/noticia/2013/02/pericia-indica-asfixia-por-cianeto-em-vitimasdaboate-kissdizpolicia.htm|?fbclid=IwAR1abmrAn8A8wBItnUKizKOFNpHvNDfzymhkjs72t2sBn72kAGT6 Hol-mA 
Pesquisa em Ensino: Tecnologia na educação: sala de aula invertida como potencializadora do ensinoaprendizagem de bioquímica

etapa, 19 (83,6\%) respostas das 23 apresentaram referência aos termos metabólicos. Sabendo que apenas a contagem de palavras não é suficiente, foram realizadas outras leituras e destacadas as frases (unidades de registro) com sentido bioquímico viável na condição apresentada (redução no metabolismo quando dormem). A seguir, foi realizada a segunda etapa da análise: exploração do material. Nesta, ficou perceptível que havia conceitos que estavam completos, outros que apresentavam ausências importantes, generalizações e por isso estavam incompletos e outros ainda em que constavam lacunas conceituais, por não apresentarem a lógica bioquímica viável como no exemplo a seguir. E1: "Começaria a falar de tecido adiposo marrom, pois é termogênico, não produz ATP, mas produz calor. Lá os ácidos graxos armazenados como gordura são detectados e sofrem betaoxidação e passam pelo ciclo de Krebs na mitocôndria." Em outras palavras, essa resposta apresentou termos metabólicos, mas com lacunas conceituais e dificuldade na contextualização.

A partir disso, as respostas foram agrupadas em categorias que reúnem um grupo de elementos da unidade de registro e facilitam a análise [14]. A seguir, elas serão apresentadas e discutidas.

- Categoria 1 (C1): Conteúdo bioquímico explicado com articulação entre os conceitos metabólicos, porém com pouca articulação com o contexto da leitura (hibernação).

- Categoria 2 (C2): Boa articulação entre conteúdo específico bioquímico com o contexto apresentado, mas com explicação metabólica insuficiente.

- Categoria 3 (C3): Lacunas conceituais, ou seja, não houve um entendimento do conteúdo específico, nem articulação do conteúdo no contexto de hibernação.

- Categoria 4 (C4): Análise e articulação completas, pois apresentaram o conhecimento bioquímico explicado de forma satisfatória e contextualizada.

Diante disso, $13(57 \%)$ respostas, demonstradas no gráfico 1, agrupam-se na categoria 4, pois associaram os termos destacados (lipólise, lipogênese, betaoxidação) com explicação coerente, evidenciando o contexto metabólico apresentado na atividade. Ou seja, os ursos armazenam uma enorme quantidade de gordura corporal quando em preparação para o seu longo sono. Por exemplo, um urso-pardo adulto consome cerca de $38.000 \mathrm{~kJ} /$ dia durante o final da Primavera e do Verão; no Inverno, esse valor é de até $84.000 \mathrm{~kJ} /$ dia. Essa mudança é uma resposta às modificações sazonais na secreção de hormônios, as quais adequam a dinâmica das vias metabólicas de reserva e utilização de energia animal para este período. 
Pesquisa em Ensino: Tecnologia na educação: sala de aula invertida como potencializadora do ensinoaprendizagem de bioquímica

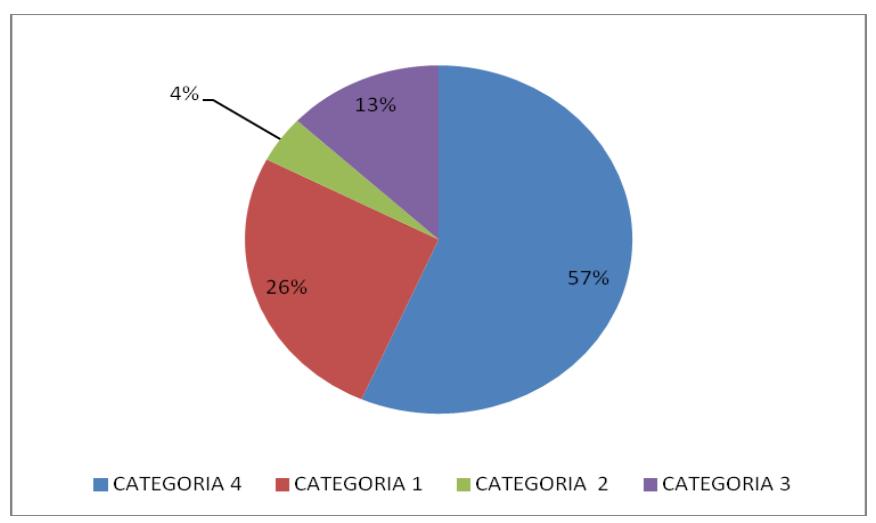

Gráfico 1: Distribuição da análise da atividade 1 com relação às categorias.

Ainda nesta etapa, verificou-se que $6(26 \%)$ respostas foram classificadas na categoria 1, pois conseguiram explicar e articular o conteúdo bioquímico de maneira correta, porém pouco o relacionaram com o contexto biológico dos ursos, e por isso, muitas vezes, explicaram as vias metabólicas, mas não contemplaram as especificidades importantes, como, por exemplo, o tipo de hormônio sinalizador para que as vias aconteçam naquele determinado período fisiológico, tornando possível que o urso hiberne. Essa realidade encontrada pode ser justificada porque os discentes, desde a escola e, inclusive, em outras disciplinas da universidade, ficam envolvidos com a metodologia meramente expositiva do conteúdo, de modo que não recebem estímulos para aplicar e enxergar os conhecimentos adquiridos em suas vidas cotidianas assim como os contextos relacionados diretamente com a sua futura profissão.

Alguns autores sustentam que a aplicação dessa proposta (SAl), mesmo com objetivos claramente expostos, para alunos com forte herança de práticas tradicionais, pode suscitar esse grau de dificuldade em conseguir trabalhar ao mesmo tempo com as partes e com o contexto (um todo) de uma atividade [18]. Por este motivo, existem discentes que, embora sejam nativos digitais, apresentam características resistentes às novas estratégias pedagógicas, como: reações emocionais desconfortantes em resposta às mudanças; foco no curto prazo em detrimento ao potencial benefício do longo prazo; e rigidez cognitiva (teimosia e falta de motivação para considerar novas ideias e perspectivas).

Diante disso, foi possível analisar também que 3 (13\%) respostas apresentaram lacunas conceituais, no sentido que, muitas vezes, mostraram, pela escrita, uma dedicação em buscar outras fontes de informação, porém não conseguiram articular tal referência adicional com as vias metabólicas inerentes ao processo de hibernação, as quais, quando citadas, não eram explicadas de forma correta. Além disso, observou-se que $1(4 \%)$ resposta obteve a atividade atribuída à categoria 2, pois conseguiu observar e 
Pesquisa em Ensino: Tecnologia na educação: sala de aula invertida como potencializadora do ensinoaprendizagem de bioquímica

destacar, no texto, as partes das vias relacionando-as, inclusive, com o contexto do urso, porém não articulou o conteúdo de maneira clara, realizando generalizações.

Nesse aspecto, pode-se salientar a importância do professor na metodologia (SAI), pois, ao contrário de críticas sobre a perda de sua importância, este cenário nos revela que, mesmo com o estudante protagonista de sua aprendizagem e pertencente a uma era tecnológica, muitas vezes ele ainda não sabe lidar com as diversas informações dispostas na rede, necessitando que o professor seja uma ponte e um mediador nessa relação estudante-tecnologia. Essa observação é constatada por autores que consideram a maior dificuldade dos alunos avaliar criticamente a informação disponível, selecionar o que é útil e entender como podem aplicar aquele conhecimento na resolução de problemas no exercício da sua profissão [19] e [20]. Com isso, uma das formas que a SAI destaca nesse papel do professor é a realização de momentos de feedback do que os alunos produziram, pois, com a Sala de Aula Invertida, esses momentos são favorecidos, porque o tempo é ampliado devido ao virtual, e porque o ambiente presencial não fica restrito apenas à exposição de conteúdo novo.

Sabendo disso, um feedback foi conduzido aos estudantes pela devolução dos textos com as correções na forma de questionamentos, e não como respostas diretas, propondo-se que estas fossem revisitadas por eles após a discussão e devolvidas para uma reavaliação pelos pesquisadores. Em seguida, foi realizado um debate, visto que o texto era apropriado para grandes articulações metabólicas e fisiológicas. Esse momento foi caracterizado por respostas às dúvidas de partes específicas do material. E, embora essa devolutiva da atividade não seja analisada aqui neste trabalho, foi observada uma significativa melhora no desenvolvimento dessa tarefa.

Dessa forma, foi visível uma aprendizagem colaborativa. Observou-se que alguns estudantes conseguiram esclarecer suas dúvidas por intermédio de perguntas, e estas serviram para aqueles que estavam mais calados, porém foi clara a mudança de expressão e eles acabaram explicando uns aos outros. Afinal:

"O feedback deve ser encarado como um processo onde tanto o professor quanto o aluno se modificam nas atividades de ensinar e aprender, o que permite a criação de um ambiente propício a discussão de ideias e ao aprimoramento de habilidades" [21]. ${ }^{\text {p. } 327}$

\subsection{Análise dos resultados da atividade 2:}

Nesta atividade, os estudantes receberam uma tabela, constante na figura 1, e tiveram que explicar as diferenças metabólicas existentes nas fibras que justificariam as 
Pesquisa em Ensino: Tecnologia na educação: sala de aula invertida como potencializadora do ensinoaprendizagem de bioquímica

concentrações das moléculas nessas diferentes fibras, relacionando a explicação com o conteúdo de respiração celular. Durante o período de realização, surgiram muitas dúvidas, por isso os estudantes realizaram questionamentos no ambiente virtual, valorizando esse momento da disciplina. Assim, as perguntas foram debatidas sobre diversos olhares e níveis de aprofundamento.

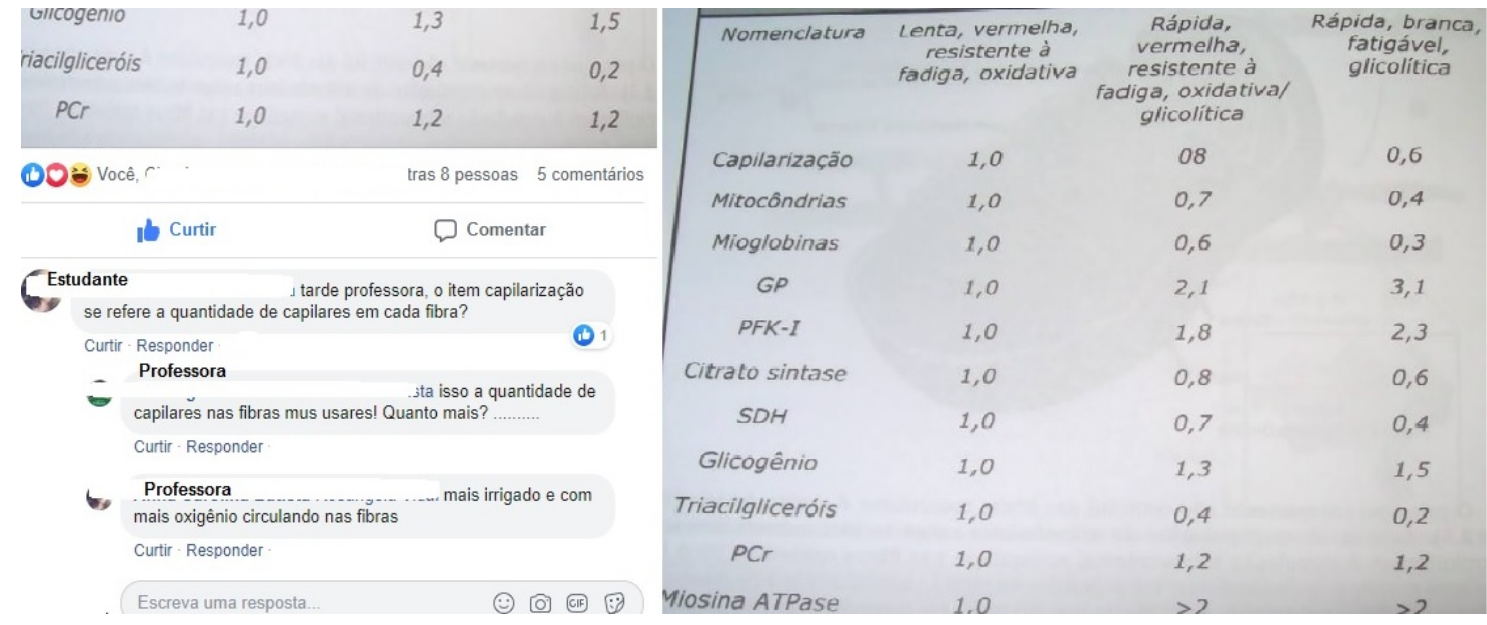

Figura 1: Registro da interação com a tabela utilizada na atividade 2.

O principal objetivo da atividade era a construção do raciocínio de que a fibra tipo I tem moléculas com concentrações diferentes das fibras tipo lla e llb devido à predominância do metabolismo aeróbico e à articulação entre o tipo de fibra e os achados da tabela. Assim como na atividade dos ursos, inicialmente foi constada nas respostas a presença das nomenclaturas apresentadas na tabela, porém ficou evidente que, embora alguns trouxessem os termos, a explicação acontecia com generalizações, sem as elucidações necessárias como mostrado a seguir. E1: "A quantidade de vasos capilares é encontrada em maior número na fibra de tipo I. Os capilares utilizam o oxigênio para gerar energia para contração dos vasos."

Percebe-se que o E1 constatou a maior concentração de capilares na fibra tipo I, porém, quando explicou essa maior concentração, apresentou uma lacuna afirmando que os capilares geram energia mediante o uso do oxigênio. Comparando com o E2 (descrito abaixo), percebe-se que, embora os dois tenham citado capilares, a explicação de E2 apresenta a lógica bioquímica e fisiológica do processo. Enquanto que E3 cita a mitocôndria, mas faz generalização com relação à produção de energia, não aprofundando que a fibra tipo I apresenta essa maior concentração devido à predominância do metabolismo aeróbico. E2: "A capilarizarão é maior nas fibras tipo I pois estes facilitam e maximizam a difusão do oxigênio até as mitocôndrias, para que seja gerada a energia necessária para a contração. As mitocôndrias tem a mesma 
Pesquisa em Ensino: Tecnologia na educação: sala de aula invertida como potencializadora do ensinoaprendizagem de bioquímica

concentração, pois oxida aerobiamente carboidratos e ácidos graxos gerando ATP para exercícios duradouros." (sic). E3: "Mitocôndria tem muito mais na fibra tipo I do que na II, porque o músculo precisa de mais mitocôndria para gerar energia já que a fibra tipo Il é utilizada para atividades de longa duração, como uma corrida". (sic)

O mesmo aconteceu na explicação de outros parâmetros nas fibras musculares em outras respostas nas seguintes categorias de análise estabelecidas:

- Categoria 1 (C1). Aprofundamento conceitual, e boa correlação entre todos os dados entre as fibras.

- Categoria 2 (C2). Sem aprofundamento conceitual, incompletas correlações entre os dados das fibras.

- Categoria 3 (C3). Lacunas conceituais, bem como contexto bioquímico incorreto.

Assim, a resposta do E1 exemplifica a categoria 3; a resposta do E2 exemplifica a categoria 1 e E3 a categoria 2. A distribuição das respostas nas categorias está organizada no gráfico 2 .

Gráfico 2: Distribuição da análise da atividade 2 com relação às categorias.

Constatou-se que $5(26 \%)$ respostas se enquadraram na categoria 1, pois estavam completas com relação ao conteúdo bioquímico na correlação entre as fibras. Isso pode ser observado a partir da análise da resposta do E4 sobre a concentração dos capilares sanguíneos. E4: "As capilarizações são maiores nas fibras musculares do tipo I por possuírem mecanismo basicamente aeróbio, necessitam de um número maior de capilares, o que acarretará diretamente num maior fluxo sanguíneo e, por conseguinte um aumento no número de oxigênio. Por outro lado, as fibras musculares do tipo IIla conseguem produzir energia independente da presença de oxigênio, através do metabolismo anaeróbico." (sic)

Além disso, $10(53 \%)$ respostas foram classificadas na categoria 2, visto que contemplavam a comparação entre as fibras, mas com alguns equívocos na explicação ou ainda por deixarem de explicar alguma molécula; e 4 (21\%) atividades apresentaram 
Pesquisa em Ensino: Tecnologia na educação: sala de aula invertida como potencializadora do ensinoaprendizagem de bioquímica

lacunas conceituais enquadrando-se, por isso, no categoria 3. Um exemplo de resposta categorizada na $\mathrm{C} 2$ pode ser visto no $\mathrm{E} 5$, pois houve dificuldade na comparação dos parâmetros no contexto exposto na atividade concernente ao parâmetro triglicerídeo: E5: "Os triacilgliceróis ou triglicerídeos apresentam-se em maior número na fibra do tipo I, eles são lipídios formados a partir de ácidos graxos. A partir da lipólise, que é um processo que acontece em estado de hipoglicemia, os triglicerídeos são quebrados formando glicerol e ácidos graxos, que por sua vez os ácidos graxos vão seguindo na respiração celular para geração de ATP". (sic)

Percebe-se que o E5 comparou e constatou que os triglicerídeos se apresentam em maior quantidade na fibra muscular tipo 1, porém em seguida, ele descreve a molécula, mas não explica o que foi pedido na atividade, fugindo do objetivo. Nesse parâmetro, ele apenas constatou, mas não analisou, ao contrário do que fez com os outros parâmetros, portanto enquadrou-se na categoria 2. Os resultados encontrados nas análises da atividade 2 também nos mostram a dificuldade que os estudantes apresentam quando dados gráficos/tabelas são colocados para a sua interpretação, isso pode ser consequência do estudo baseado em memorização e não em análises de dados, análise de contextos biológicos.

Esses resultados demonstram que os estudantes não encontram facilidade em correlacionar as disciplinas, nesse caso a Bioquímica e a Histologia, ou seja, não apresentam uma visão interdisciplinar. Isso pode ser justificado pela hiper fragmentação do currículo, que faz parte da vida do estudante desde a escola básica, visto que os currículos escolares seguem uma linearidade [22], nos quais, historicamente, foi estabelecido que é impossível aprender determinado conteúdo, sem antes conhecer o seu "antecessor", mas isso parece não ser verdadeiro na maioria dos casos, portanto, essa rigidez no encadeamento dos tópicos desenvolvidos parece desnecessária [23].

Ainda nesse contexto da visão interdisciplinar, vale ressaltar que dificuldades como essa encontrada na pesquisa entram em um ciclo, no qual esses futuros professores podem apresentar maior bloqueio de ensinar de maneira interdisciplinar, formando, com isso, novos estudantes com os mesmos déficits. Porém, práticas inovadoras como a da pesquisa podem fomentar o interesse desses alunos, fazendo com que a visão interdisciplinar dos conteúdos deixe de ser um obstáculo na aprendizagem [23].

\subsection{Análise dos resultados da atividade 3:}

Nesta atividade, os estudantes receberam a proposta para experienciar outras 
Pesquisa em Ensino: Tecnologia na educação: sala de aula invertida como potencializadora do ensinoaprendizagem de bioquímica

dimensões da aprendizagem. Foi pedido que gravassem um vídeo ou um áudio (esta flexibilidade de formato foi em atendimento às demandas dos estudantes mais tímidos), pois nas metodologias ativas o professor é, naturalmente, levado a trabalhar a flexibilidade para que seus alunos sejam protagonistas e aprendam de fato [4].

A proposta da atividade foi a simulação de uma entrevista para uma TV ou rádio locais, em que eles seriam entrevistados, enquanto biólogos, sobre o caso do incêndio da boate Kiss e suas implicações metabólicas nos organismos das pessoas que foram a óbito. Tinham que explicar os efeitos metabólicos (micro) que causaram as mortes por asfixia (macro), pois as causas primárias dessas mortes tinham como uma das bases de explicação teórica a deficiência da respiração celular.

É importante, ainda na academia, aprender com situações reais da vida profissional, como por exemplo, se comunicar-se com a sociedade por intermédio de uma linguagem simples, porém com bases científicas. A atividade teve como resultado a produção de vídeos (postados no AVA) e áudios (enviados à professora pelo aplicativo WhatsApp) de excelente qualidade que foram utilizados como instrumentos avaliativos da disciplina. Sendo assim, além de receberem uma devolução com avaliação do professor, os estudantes também realizaram feedback entre eles no próprio AVA, comentando o que acharam dos vídeos produzidos. Para análise segundo a metodologia de Bardin [12], o material produzido foi transcrito. Na pré-análise, foram identificadas algumas unidades de registro como "causa da morte"; "inibição oxidativa"; "cianeto"; "ferro"; "hemoglobina"; "cadeia transportadora de elétrons" e "oxigênio", de forma que o número de registros extrapolou a quantidade de resposta. Aprofundando a análise das respostas, foi possível verificar, assim como na atividade anterior, aquelas com profundidade e lógica bioquímica e contextual possíveis, aquelas com generalizações e linguagem técnica excessiva e aquelas com lacunas conceituais.

Pode ser observado nas respostas de E1, E2 e E3, que foram agrupadas, respectivamente, em C1; C3; C2. E1: "A espuma da boate Kiss era altamente inflamável, quando entra em combustão, ela libera gás cianídrico. O cianeto basicamente atua inibindo a cadeia respiratória ao se ligar ao $\mathrm{Fe} 3+$ da citocromo $\mathrm{C}$ oxidase que impede que este retorne a seu estado ferroso. Assim uma pessoa contaminada pelo cianeto, mesmo que ela respire desesperadamente ela não vai conseguir completar a respiração celular, até chegar à morte."; (sic) E2: O cianeto é uma substância que quando inalado reage com a acidez do estômago. Quando ele entra na corrente sanguínea ele se liga ao ferro da hemoglobina, os glóbulos vermelhos."; (sic) E3: "O cianeto tem uma grande afinidade pelo 
Pesquisa em Ensino: Tecnologia na educação: sala de aula invertida como potencializadora do ensinoaprendizagem de bioquímica

ferro mais três, no entanto, não pelo ferro mais dois. E o que acontece? Ele se liga rapidamente ao ín férrico do citocromo c oxidase fazendo o que impeça que retorne ao estado ferroso. Todavia isso bloqueia a cadeia respiratória e por conseguinte bloqueia também a síntese acoplada de ATP." (sic) A partir das semelhanças, as falas foram agrupadas nas seguintes categorias e estão distribuídas no gráfico 3 .

- Categoria 1 (C1). Demonstrar capacidade de articulação entre o conhecimento científico e o fato ocorrido na boate, com linguagem acessível e conteúdo corretamente explicado.

- Categoria 2 (C2). Conceitos bioquímicos explicados, porém, com pouca articulação com o fato ocorrido, dificultando o entendimento de leigos.

- Categoria 3 (C3). Conteúdo bioquímico explicado de forma incompleta e com lacunas conceituais.

Observou-se um elevado teor de criatividade, característica importante para os futuros professores que serão, além de uma melhora, com relação à atividade anterior, no desenvolvimento dos conteúdos específicos e foco no contexto. Em outras palavras, uma análise detalhada desta atividade mostrou que, na maioria dos casos, a partir da avaliação processual e não somente pontual, os estudantes conseguiram evoluir de uma atividade para outra.



Gráfico 3: Distribuição da análise da atividade 3 com relação às categorias.

Em comparação com a atividade anterior, pode-se observar uma evolução significativa na aprendizagem, visto que as atividades classificadas com o conteúdo bioquímico completo passaram de $5(26,32 \%)$ para 13 (65\%). A melhora pode ser explicada principalmente pela estratégia escolhida: a gravação de vídeos e áudios (recursos que fazem parte do cotidiano dos alunos); pela situação colocada na atividade: notícia de um fato real e trágico e pela instigação de se colocar diante de uma situação nova (gravar uma entrevista) que pode acontecer na futura prática desse professor de Biologia.

Com essa aproximação da realidade, foi perceptível, no material produzido, que os 
Pesquisa em Ensino: Tecnologia na educação: sala de aula invertida como potencializadora do ensinoaprendizagem de bioquímica

alunos estavam à vontade e desenvolveram habilidades como a criatividade, ao utilizarem desenhos nos vídeos e diferentes tons de voz nos áudios, para que o expectador compreendesse os motivos biológicos que causaram a morte de vários jovens no caso em estudo. Isso é corroborado pela afirmação de que a educação precisa ser útil para a vida, de modo que os estudantes possam articular o conhecimento construído com possibilidades reais de aplicação prática, ou seja, aprender com sentido a partir da contextualização [24].

Essa atividade alcançou os objetivos pretendidos, como, explorar a percepção auditiva daqueles alunos que aprendem melhor com palestras, discussão em grupo, rádio, e-mail, usando telefones celulares, falando, conversando na web, além de constituir-se num treino para que futuros professores façam uso de ferramentas de áudio, como os podcasts, para utilizar com estudantes com deficiência auditiva ou visual, colaborando assim para a acessibilidade e inclusão ao conhecimento. A preferência aural inclui falar em voz alta, bem como falar consigo mesmo. Muitas vezes, as pessoas com essa preferência querem resolver as coisas falando primeiro, em vez de resolverem suas ideias e depois falar. Elas podem dizer novamente o que já foi dito, ou fazer uma pergunta óbvia e anteriormente respondida. Elas precisam dizer para si mesmas para assimilarem a informação [16].

\section{Considerações Finais}

A pesquisa apresenta dados nos quais foi possível perceber que a metodologia da Sala de Aula Invertida favoreceu o aprendizado significativo da bioquímica, pois trouxe diferentes contextos biológicos que permitem uma materialização dos conteúdos abstratos, como também fortaleceu o feedback. Houve igual favorecimento na questão do tempo de entrega das produções avaliadas, bem como de momentos em que os estudantes puderam revisitar suas construções e refazer seus percursos de aprendizagem, pelo reconhecimento dos seus erros, como foi o caso da atividade sobre a betaoxidação de animais hibernantes, que receberam de volta para que fosse revista/refeita.

Outro ponto a ser destacado é a dificuldade que os alunos apresentam ao utilizar o conhecimento em situações de interpretações de dados científicos, como foi possível observar nos resultados da atividade 2 (tabela de fibras musculares), na qual $53 \%$ das respostas da turma foram caracterizados na categoria 2, como sendo sem aprofundamento conceitual, incompletas correlações entre os dados das fibras.

Pode-se destacar, no entanto, que nesta metodologia, o diálogo foi favorecido 
Pesquisa em Ensino: Tecnologia na educação: sala de aula invertida como potencializadora do ensinoaprendizagem de bioquímica

também porque, por um lado, a SAI permite que o aluno chegue à sala de aula com conhecimento prévio do conteúdo, que o deixa seguro para esclarecer dúvidas, expor ideias e; por outro, o professor aufere mais possibilidades para dar significado ao conteúdo, e se apresentar como um mediador das atividades.

Apesar desses achados motivadores apresentados nos resultados da pesquisa, vale evidenciar a existência de alunos com estilos de aprendizagem que são mais favorecidos por um ensino expositivo-dialogado, e esse pode ser o motivo pelo qual alguns estudantes têm dificuldade em associar as vias metabólicas com as situações reais apresentadas nas atividades. Então, cabe ao professor ser sensível a essa realidade cognitiva, que frequentemente é fruto de uma vida escolar norteada pela ensinagem que privilegia a memorização, que leva o estudante a desenvolver mais o estilo baseado nesta característica. Por esse motivo, é interessante o professor mesclar a aula, sempre que possível, com diferentes estilos de aprendizagem.

\section{Referências}

[1] Morais C, Alves P, Miranda L. Valorização dos Ambientes Virtuais de Aprendizagem por Professores do Ensino Superior. IN: Atas da $8^{\text {a }}$ Conferência Ibérica de Sistemas e Tecnologias de Informação; 19 a 23 de junho de 2013, Lisboa, Portugal, 2013.

[2] Camargo F, Daros T. A sala de aula inovadora: Estratégias pedagógicas para fomentar o aprendizado ativo. Porto Alegre: Penso, 2018.

[3] Abreu JRP. Contexto Atual do Ensino Médico: Metodologias Tradicionais e Ativas - Necessidades Pedagógicas dos Professores e da Estrutura das Escolas. 2011. 105f. Dissertação (Programa de PósGraduação em Ciências da Saúde) - Universidade Federal do Rio Grande do Sul. Porto Alegre, 2009.

[4] Berbel N. As metodologias ativas e a promoção da autonomia dos estudantes. Semina: Ciências Sociais e Humanas, Londrina, 2011; 32(1): 25-40.

[5] Freire P. Pedagogia da Autonomia: Saberes necessários à prática educativa. $51^{\mathrm{a}}$ ed. Rio de Janeiro: Paz \& Terra, 2015.

[6] Bacich L, Neto AT, Trevisani FM. Ensino Híbrido: personalização e tecnologia na educação. Porto Alegre: Penso, 2015.

[7] Horn MB, Staker H. Blended: usando a inovação disruptiva para aprimorar a educação. Tradução: Maria Cristina Gularte Monteiro. Porto Alegre: Penso, 2015.

[8] Valente JA. Blended learning e as mudanças no ensino superior: a proposta da sala de aula invertida. Educar em Revista, Curitiba, 2014; (4), 79-97.

[9] Villardi ML, Cyrino EG, Berbel NAN. A problematização em educação em saúde: percepções dos professores tutores e alunos. São Paulo: Editora UNESP; São Paulo: Cultura Acadêmica, 2015.

[10] Catholico RAR, Oliveira Neto JD. O inventário dos estilos de aprendizagem em um curso técnico de eletroeletrônica. Revista Eletrônica de Educação e Tecnologia do Senai-SP, São Paulo, 2009; 3: 1-14.

[11] Oliveira MM. Como fazer pesquisa qualitativa. Recife: Bagaço, 2005.

[12] Bardin, L. Análise de conteúdo. SP: Edições 70, 2011.

[13] Tozoni-Reis MFC. Metodologia da Pesquisa. 2. ed. Curitiba: IESDE Brasil S.A., 2009. 
Pesquisa em Ensino: Tecnologia na educação: sala de aula invertida como potencializadora do ensinoaprendizagem de bioquímica

[14] Oliveira E, Ens RT, Andrade DBSF, Mussis CR. Análise de conteúdo e pesquisa na área da Educação. Revista Diálogo Educacional, Curitiba, 2003; 4(9): 11-27.

[15] Fleming N D. Teaching and learning styles: VARK strategies. Christchurch, New Zealand: N. D. Fleming, 2001.

[16] Souza AG, Rosa RCR, Rocha SF. Perfil dos estilos de aprendizagem segundo o modelo V.A.R.K numa amostra de trombonistas: um estudo piloto. In: VI Simpósio Científico da ABT, 2017.

[17] Nelson DL, Cox MM, Termignoni C. Princípios de bioquímica de Lehninger, 2014.

[18] Junior AAS, Souza GPVA, Santos EA. Desafios da aplicação da sala de aula invertida no ensino de bioquímica. In: V CONEDU (CONGRESSO NACIONAL DE EDUCAÇÃO), 2018.

[19] Mitre SM, Siqueira-Batista R, Girardi-de-Mendonça JM, Morais-Pinto NM, Meirelles CAB, Pinto-Porto C, Moreira T, Hoffmann LMA. Metodologias ativas de ensino-aprendizagem na formação profissional em saúde: Debates atuais. Ciência \& Saúde Coletiva, 2008; 13b(2): 2133- 2144.

[20] Costa CHC, Dantas Filho FF, Moita FMGSC. Marvinsketch e kahoot como ferramentas no ensino de isomeria. Holos, 2017; 1: 31- 43.

[21] Borges MC, Miranda CH, Santana RC, Bollela VR. Avaliação formativa e feedback como ferramenta de aprendizado na formação de profissionais da saúde. Revista da Faculdade de Medicina de Ribeirão Preto e do Hospital das Clínicas da FMRP, Ribeirão Preto, 2014; 3(47): 324-331.

[22] Machado, Nilson José. Educação: projetos e valores. 3. ed. São Paulo: Escrituras, 2000.

[23] Augusto TGS, Caldeira AMA. Dificuldades para a implantação de práticas interdisciplinares em escolas estaduais, apontadas por professores da área de ciências da natureza. Investigações em Ensino de Ciências, 2007; 12(1): 139-154.

[24] Diesel A, Baldez ALS, Martins SN. Os princípios das metodologias ativas de ensino: uma abordagem teórica. Revista Thema, 2017; 14(1): 268-288. 